\title{
Detection of antibody therapy-induced anti- tumor immune responses using anti-CD8 immuno-pet
}

\author{
Richard Tavare ${ }^{1 *}$, Helena Escuin-Ordinas ${ }^{1}$, Melissa McCracken ${ }^{1}$, Kirstin Zettlitz $^{1}$, Felix Salazar ${ }^{1}$, Owen Witte $^{1}$, \\ Antoni Ribas ${ }^{2}$, Anna $\mathrm{Wu}^{1}$ \\ From 30th Annual Meeting and Associated Programs of the Society for Immunotherapy of Cancer (SITC 2015) \\ National Harbor, MD, USA. 4-8 November 2015
}

Tumor heterogeneity and the dynamic tumor immune microenvironment have become important topics in the field of cancer immunotherapy. The ability to noninvasively monitor immune cells in vivo via surface markers on immune cell subsets using immuno-positron emission tomography (immuno-PET) is an attractive means of visualizing both systemic and intratumoral alterations in immune cell numbers and localization during experimental immunotherapies. Due to the critical role of tumor-infiltrating cytotoxic $\mathrm{CD} 8^{+} \mathrm{T}$ cells in anti-tumor immune responses, a radiolabeled anti-CD8 antibody fragment (cys-diabody) was developed for immuno-PET detection of cytotoxic $\mathrm{CD}^{+} \mathrm{T}$ cells in vivo. The antiCD8 cys-diabody radiolabeled with ${ }^{89} \mathrm{Zr}$ using the bifunctional chelator deferoxamine-maleimide enabled visualization of the spleen and lymph nodes in normal mice; specificity was confirmed in CD8-blocking studies. Next, anti-CD8 immuno-PET was shown to specifically detect tumor-infiltrating lymphocytes in immunotherapy models including agonistic antibody therapy (anti-CD137/ 4-1BB) and checkpoint blockade antibody therapy (antiPD-L1). Balb/c mice bearing week old syngeneic CT26 colorectal tumors were treated with either anti-CD137 or anti-PD-L1 antibody therapy and imaged at day 8 posttherapy. All mice treated with anti-CD137 therapy demonstrated tumor regression and increased anti-CD8 immuno-PET targeting in the tumors of mice treated with anti-CD137 therapy compared to the tumor of untreated mice. Ex vivo biodistribution confirmed enhanced tumor uptake of anti-CD137 treated versus untreated mice $(15 \pm 5.5 \% \mathrm{ID} / \mathrm{g}$ versus $6.0 \pm 0.83 \% \mathrm{ID} / \mathrm{g}$, respectively). Anti-CD8 immuno-PET of untreated mice demonstrated a rim of activity around the tumor while anti-CD137 treated mice demonstrated enhanced intratumoral uptake. The increase in $\mathrm{CD} 8^{+}$tumor-infiltrating lymphocytes was validated by both flow cytometry and immunohistochemistry. About $30 \%$ of mice treated with anti-PD-L1 therapy demonstrated tumor regression and were grouped into non-responders (average tumor diameter $>8 \mathrm{~mm}$ ) and responders (average tumor diameter $<$ $8 \mathrm{~mm})$. Anti-PD-L1 non-responders and responders had tumor anti-CD8 immuno-PET uptake of $6.4 \pm 1.5 \% \mathrm{ID} / \mathrm{g}$ and $11.27 \pm 2.7 \% \mathrm{ID} / \mathrm{g}$ as determined from ex vivo biodistribution analysis, respectively, demonstrating enhanced $\mathrm{CD}^{+} \mathrm{T}$ cell infiltration in responding mice that was confirmed by flow cytometry. Anti-CD8 immuno-PET was successful in the noninvasive detection of tumor-infiltrating $\mathrm{CD}^{+} \mathrm{T}$ cells in two differing antibody-based immunotherapy strategies that have shown promise in the clinic.

\section{Authors' details}

'University of California, Los Angeles, Los Angeles, CA, USA. ${ }^{2}$ University of California at Los Angeles Medical Center, Los Angeles, CA, USA.

Published: 4 November 2015

doi:10.1186/2051-1426-3-S2-P391

Cite this article as: Tavare et al:: Detection of antibody therapy-induced anti-tumor immune responses using anti-CD8 immuno-pet. Journal for ImmunoTherapy of Cancer 2015 3(Suppl 2):P391.

'University of California, Los Angeles, Los Angeles, CA, USA

Full list of author information is available at the end of the article 